\title{
Article
}

\section{Pacing Profiles of Middle-Distance Running World Records in Men and Women}

\author{
Arturo Casado ${ }^{1}\left(\mathbb{D}\right.$, Fernando González-Mohíno ${ }^{2,3, *}$, José María González-Ravé ${ }^{(\mathbb{D}}$ and Daniel Boullosa and $^{4}$ \\ 1 Center for Sport Studies, Rey Juan Carlos University, 28933 Madrid, Spain; arturo.casado@urjc.es \\ 2 Sport Training Laboratory, Faculty of Sport Sciences, University of Castilla la Mancha, 45004 Toledo, Spain; \\ josemaria.gonzalez@uclm.es \\ 3 Facultad de Ciencias de la Vida y de la Naturaleza, Universidad Nebrija, 28240 Madrid, Spain \\ 4 Integrated Institute of Health, Federal University of Mato Grosso do Sul, Campo Grande 79070-900, Brazil; \\ daniel.boullosa@gmail.com \\ 5 College of Healthcare Sciences, James Cook University, Townsville 4811, Australia \\ * Correspondence: Fernando.gmayoralas@uclm.es; Tel.: +34-690216354
}

Citation: Casado, A.;

González-Mohíno, F.; González-Ravé, J.M.; Boullosa, D. Pacing Profiles of Middle-Distance Running World Records in Men and Women. Int. J Environ. Res. Public Health 2021, 18, 12589. https://doi.org/10.3390/ ijerph182312589

Academic Editor: Paul B. Tchounwou

Received: 4 November 2021

Accepted: 27 November 2021

Published: 29 November 2021

Publisher's Note: MDPI stays neutral with regard to jurisdictional claims in published maps and institutional affiliations.

Copyright: (C) 2021 by the authors. Licensee MDPI, Basel, Switzerland. This article is an open access article distributed under the terms and conditions of the Creative Commons Attribution (CC BY) license (https:// creativecommons.org/licenses/by/ $4.0 /)$.

\begin{abstract}
The aims of the current study were to compare the pacing patterns of all-time $800 \mathrm{~m}$, $1500 \mathrm{~m}$ and mile running world records (WRs) and to determine whether differences exist between sexes, and if $800 \mathrm{~m}$ and $1500 \mathrm{~m}$ WRs were broken during championship or meet races. Overall and lap times for men and women's 800 m, 1500 m, and mile WRs from World Athletics were collected when available and subsequently compared. A fast initial $200 \mathrm{~m}$ segment and a decrease in speed throughout was found during $800 \mathrm{~m}$ WRs. Accordingly, the first $200 \mathrm{~m}$ and $400 \mathrm{~m}$ were faster than the last $200 \mathrm{~m}$ and $400 \mathrm{~m}$, respectively $(p<0.001,0.77 \leq \mathrm{ES} \leq 1.86)$. The first $400 \mathrm{~m}$ and $409 \mathrm{~m}$ for $1500 \mathrm{~m}$ and mile WRs, respectively, were faster than the second lap $(p<0.001$, $0.74 \leq \mathrm{ES} \leq 1.46$ ). The third $400 \mathrm{~m}$ lap was slower than the last $300 \mathrm{~m}$ lap and $400 \mathrm{~m}$ lap for $1500 \mathrm{~m}$ and mile WRs, respectively $(p<0.001,0.48 \leq \mathrm{ES} \leq 1.09)$. No relevant sex-based differences in pacing strategy were found in any event. However, the first $409 \mathrm{~m}$ lap was faster than the last $400 \mathrm{~m}$ lap for men but not for women during mile WRs. Women achieved a greater \% of WRs than men during championships ( $80 \%$ vs. $45.83 \%$ in the $800 \mathrm{~m}$, and $63.63 \%$ vs. $31.58 \%$ in the $1500 \mathrm{~m}$, respectively). In conclusion, positive, reverse J-shaped and U-shaped pacing profiles were used to break 800 m, men's mile and $1500 \mathrm{~m}$, and women's mile WRs, respectively. WRs are more prone to be broken during championships by women than men.
\end{abstract}

Keywords: pacing; middle-distance running; world record; athletics

\section{Introduction}

Pacing, described as the work or effort distribution over a race, has been extensively studied over the last 40 years in endurance sports [1]. There is consensus that pacing is a prerequisite to achieve successful endurance performance, and that depends on several internal (i.e., muscle fatigue [2], and psychophysiological variables [3]) and external (i.e., tactics [4], and ambient conditions, such as wind resistance [5]) factors [6]. Ideally, an even effort distribution would be the most optimal pacing strategy from an energetic point of view [7], but the accumulated evidence demonstrates that different pacing profiles can be observed mostly depending on the distance/duration of the race [8].

The analysis of pacing strategies of track running world records (WRs) is an excellent paradigm of study because they were used to achieve the most optimal and outstanding performances in history. These strategies may be considered by runners exhibiting lower performance and help them to improve it through a learning process. Interestingly, while cross-sectional data suggest a reduced variability of velocity with WRs improvements over different distances $[7,9]$, a more recent analysis of WRs performed by the same athletes suggest that these individuals' running performances can be improved without changes in 
their own pacing strategies [10]. Pacing strategies in men during $800 \mathrm{~m}$ [11], $1500 \mathrm{~m}$ [12] and mile [13] running WRs were previously studied. However, the analysis of men's $800 \mathrm{~m}$ WRs is not updated in the current literature, with the latest three WRs achieved by Kenyan runner David Lekuta Rudisha. Therefore, considering the new WRs and the potential impact of exceptional WR holders on performance and pacing, such as Rudisha for $800 \mathrm{~m}$, it is required an updated analysis of pacing strategies of middle-distance running races in which the contribution of anerobic capacity is more relevant [14] than in other endurance running races. In addition, to date, no previous study has analyzed the pacing strategies during women's $800 \mathrm{~m}$ and $1500 \mathrm{~m}$ WRs.

Sex influence on pacing behavior is also another topic of interest in pacing research, as it would be expected that internal factors associated to sex differences may be relevant. A previous study compared both men's and women's pacing strategies from marathon WRs [15] and found that women tended to follow a less uniform pace, while men typically adopted a more even pace with a fast end spurt at the final stages of the race. Regarding middle-distance running WRs, Foster et al. [7] observed that the pacing pattern of men's mile WRs is characterized by a progressive reduction in the within-lap variation of pace, while in women, the pattern of lap times has almost not changed over time, likely secondary to a lack of performance depth in the women's fields. However, this previous analysis of mile WRs in women was conducted up to 1996. In addition, a sex-based comparison between $800 \mathrm{~m}$ and $1500 \mathrm{~m}$ WRs is warranted to better understand whether physiological differences between sexes influence pacing patterns over middle-distance runs.

The use of pacemakers strongly assist for the achievement of the fastest possible finishing performance by means of a reduction in the cognitive load associated to a continuous decision-making process $[3,16]$, and also allowing WR aspirants to take advantage of drafting $[3,5]$. However, pacemakers are typically used during meets (i.e., non-championship races in which the main goal is to achieve the fastest finishing performance) rather than championship races [8]. In addition, setting a WR is a very different goal to winning a gold medal during major championships. Therefore, it is expected that middle-distance running WRs were achieved during meets rather than championship races. However, WRs may also be achieved during championship races, at which world-class athletes typically peak. Nonetheless, to date, no previous study analyzed the type of race (i.e., meets vs. championship races) in which WRs were broken.

Therefore, the aims of the current study were (1) to describe and compare the pacing profiles of all-time middle-distance running WRs, (2) to verify whether differences exist between men and women, and (3) to determine whether $800 \mathrm{~m}$ and $1500 \mathrm{~m}$ WRs were broken during either championship or meet races.

\section{Materials and Methods}

\subsection{Pacing Data}

Overall and split times recorded during $800 \mathrm{~m}$ (21 men and 10 women), $1500 \mathrm{~m}$ (37 men and 10 women) and mile (32 men and 9 women) world records (WRs) from the World Athletics (WA, formerly International Amateur Athletic Federation (IAAF)) era until 2014 were collected from the Hymans and Metrahazi [17] database when available. WRs ratification by WA and 2 other WRs broken from 2015 to 2020 were extracted from the WA website (www.worldathletics.org (accessed date 20 December 2020)).

\subsection{Design and Methodology}

The present study followed an observational approach. In the men's $800 \mathrm{~m}$ event, 24 WRs were ratified by WA from 1912 to 2012. However, WRs with split times in yards or without split times were excluded. Finally, $400 \mathrm{~m}$ lap times were available for 13 races, while $200 \mathrm{~m}$ lap times were available for the remaining 8 races. They represented $87.5 \%$ of all WRs. In women's 800 m events, 29 WRs from 1922 to 1983 were ratified by WA. However, split times were only available for $10 \mathrm{WRs}$, which represented $34.5 \%$ of all WRs. Finally, $200 \mathrm{~m}$ and $400 \mathrm{~m}$ lap times were available in 2 and $8 \mathrm{WRs}$, respectively. 
In the men's 1500 m event, 38 WRs were ratified by WA from 1912 to 1999. Lap times ( $3 \times 400 \mathrm{~m}$ lap times and the last $300 \mathrm{~m}$ ) were available for 37 men's WRs from 1917 to 1998 . They represented $97.4 \%$ of all WRs. In the women's 1500 m event, 14 WRs were ratified by the WA from 1967 to 2015. Only split times for 11 WRs were available. They represented $78.6 \%$ of all WRs.

In the men's mile event, 32 WRs were ratified by WA from 1913 to 1999. Lap (a first lap of $409 \mathrm{~m}$ and $3 \times 400 \mathrm{~m}$ laps) times were available in all these WR. In the women's mile event, 14 WRs from 1967 to 2019 were ratified by WA. Split times were available in 10 WRs, which represented $71.4 \%$ of all WRs.

Each lap time was expressed as a percentage of the average race speed (\%RS) for further comparisons. Categorization of the different pacing strategies was conducted according to the statistical differences found between lap times. For example, a U-shaped pacing strategy during either $1500 \mathrm{~m}$ or mile events is considered if the first and second laps are covered at significantly faster paces than those during the second and third laps, without significant differences between paces during the first and last laps. Rather, a reverse J-shaped pacing strategy is considered if the first and last laps are covered at significantly faster paces than those during the second and third laps, and the first lap is completed at a significantly faster pace than that during the last lap.

\subsection{Statistical Analysis}

All data are presented as mean and standard deviation (mean \pm SD). Data were checked for normality of distribution, equality of variances, and assumption of sphericity. When the sphericity assumption was violated, the Greenhouse-Geisser correction was employed. A 2-factor analysis of variance (ANOVA) with repeated measures with 'race average speed at each lap' as the between laps' factor and sex as the between subjects' factor was conducted to determine the differences between $\%$ RS at each lap and between sexes. A Bonferroni post hoc correction was used in all pairwise comparisons. Effect sizes (ES) were calculated using partial eta-squared (१p2) for the repeated measured ANOVA test, and Cohen's d [18] for the Bonferroni post hoc test. The $\eta p 2$ was considered to be small $(0.01)$, moderate $(0.01-0.06)$ or large $(>0.15)$ [19]. The Cohen's d was considered to be small (0.21-0.50), moderate (0.51-0.80) or large (>0.80) [18]. Statistical significance was set at $p<0.05$. All analyses were performed with the JASP software (version 0.13.1 for Mac OS, JASP Team, Amsterdam, the Netherlands). Figures were performed with the Graph Pad Prism software (version 8.0 for Mac) (San Diego, CA, USA).

\section{Results}

The repeated measures ANOVA revealed a non-significant difference in \%RS between sexes for all middle-distance running events (Table 1). However, there were significant differences in \%RS within all middle-distance events in both sexes.

Table 1. Repeated measures ANOVA outcomes of lap and lap and sex interaction.

\begin{tabular}{ccccccccccc}
\hline & & \multicolumn{8}{c}{ Repeated Measures ANOVA } \\
\hline & \multicolumn{1}{c}{} & \multicolumn{7}{c}{ Between Laps } & \multicolumn{5}{c}{ Lap and Sex Interaction } \\
\hline Event & $\begin{array}{l}\text { Number } \\
\text { of Laps }\end{array}$ & $\begin{array}{c}\text { df } \\
\text { Residual }\end{array}$ & $p$ & F & df & ES & $p$ & F & ES \\
\hline \multirow{2}{*}{$800 \mathrm{~m}$} & 2 & 19 & $<0.001$ & 31.55 & 1 & 0.623 & 0.978 & 0.00 & 0.000 \\
$1500 \mathrm{~m}$ & 4 & 21 & $<0.001$ & 10.029 & 3 & 0.561 & 0.483 & 0.483 & 0.047 \\
Mile & 4 & 138 & $<0.001$ & 31.40 & 3 & 0.397 & 0.358 & 1.08 & 0.014 \\
\hline
\end{tabular}

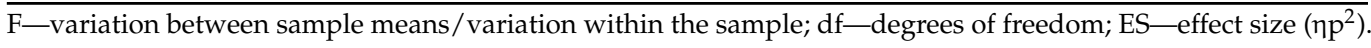

In the $800 \mathrm{~m}$ event (Figure 1), the first $400 \mathrm{~m}$ lap was covered at a significantly faster speed than the second $400 \mathrm{~m}$ lap $(p<0.001$, ES $=0.99$ and 0.77 for men and women, 
respectively). The first $200 \mathrm{~m}$ lap was also covered at a significantly faster speed than the fourth $200 \mathrm{~m}$ lap for men $(p<0.001, \mathrm{ES}=1.86)$.
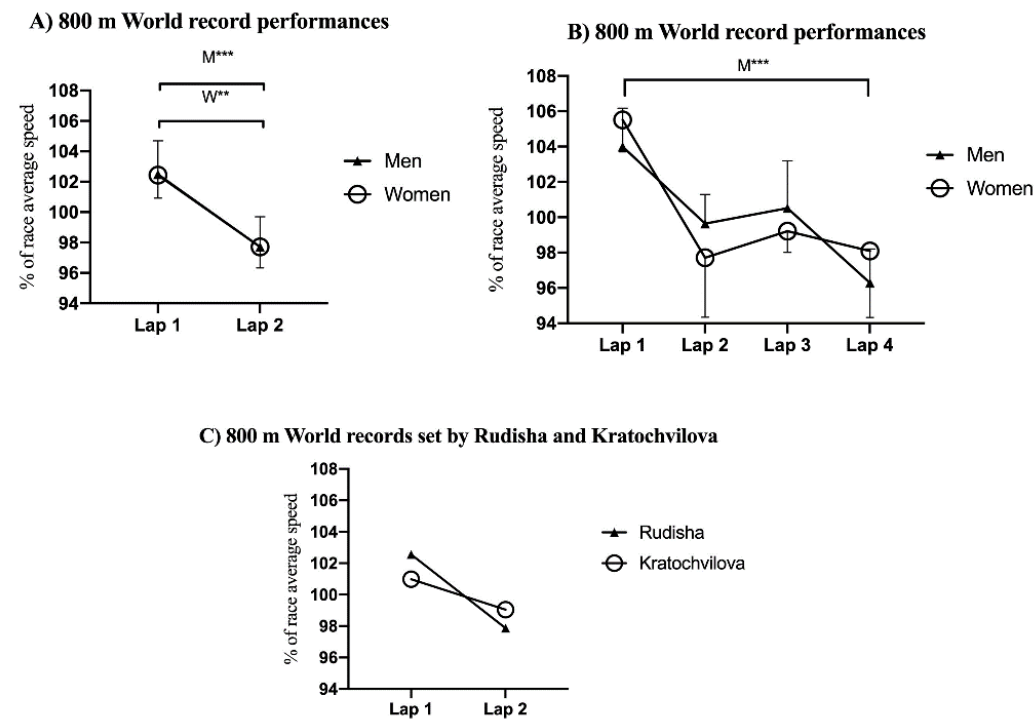

Figure 1. Mean and standard deviation of (A) average race speed of two $400 \mathrm{~m}$ laps, (B) four $200 \mathrm{~m}$ laps during male and female $800 \mathrm{~m}$ world record performances, and (C) world records set by Rudisha and Kratochvilova with two $400 \mathrm{~m}$ laps. ${ }^{* *} p<0.01 ;{ }^{* * *} p<0.001$.

In the $1500 \mathrm{~m}$ event (Figure 2), the first lap was covered at a significantly faster speed than the second lap $(p<0.001$, ES $=0.91$ and 0.78 for men and women, respectively). The second lap was covered at a significantly slower speed than the last $300 \mathrm{~m}$ lap $(p<0.001$ and $p=0.05$, ES $=1.02$ and 0.65 for men and women, respectively). The third lap was covered at a significantly slower speed than the last $300 \mathrm{~m}$ split $(p<0.001, \mathrm{ES}=0.86$ and 0.48 for men and women, respectively). There were no differences between $\% R S$ at the first lap and the last $300 \mathrm{~m}$ lap for men or women.
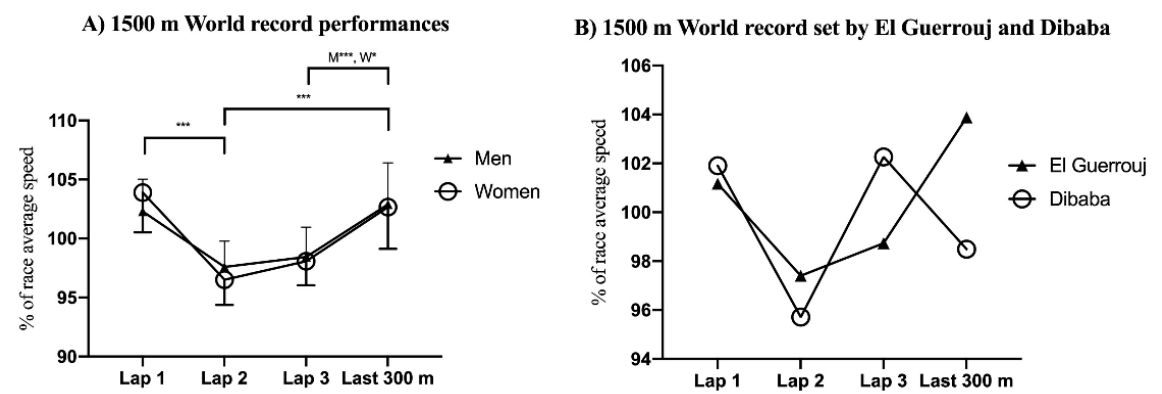

Figure 2. Mean and standard deviation of (A) average race speed of three $400 \mathrm{~m}$ laps and last $300 \mathrm{~m}$ during men and women's $1500 \mathrm{~m}$ world record performances (A), and (B) world records set by El Guerrouj and Dibaba. * $p<0.05 ;{ }^{* *} p<0.001$.

In the mile event, the first $409 \mathrm{~m}$ lap was covered at a significantly faster speed than the second lap $(p<0.001, \mathrm{ES}=1.46$ and 0.74 for men and women, respectively), and also than the third lap ( $p<0.001$, ES $=1.62$ and 0.78 for men and women, respectively). The men's first lap was faster than the last lap $(p<0.05$, ES $=0.53)$, the second lap was slower than the last lap $(p<0.001$, ES $=0.93)$, and the third lap was slower than the last lap $(p<0.001, \mathrm{ES}=1.09)($ Figure 3$)$. 
A) Mile World record performances

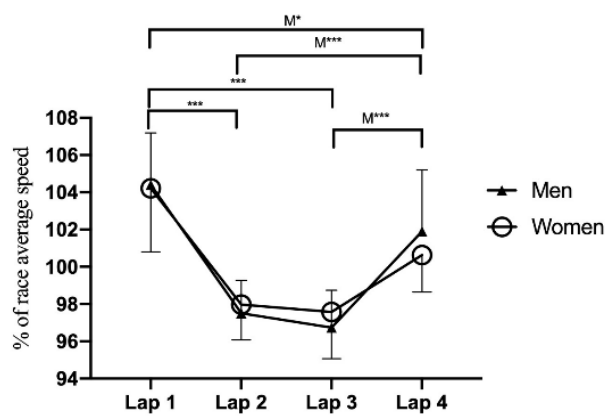

B) Mile World records set by El Guerrouj and Hassan

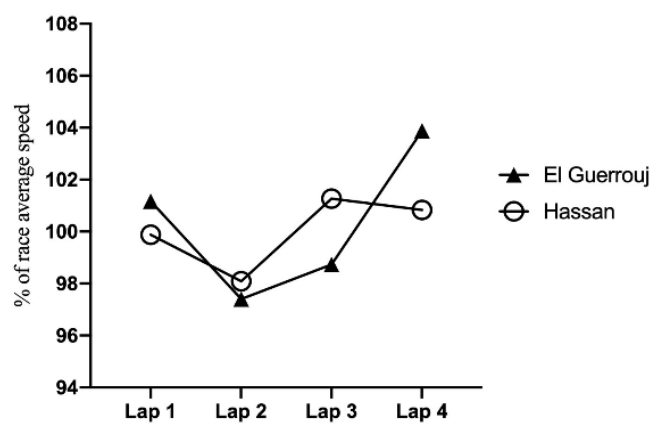

Figure 3. Means and standard deviation of (A) average race speed of first $409 \mathrm{~m}$ lap, and three $400 \mathrm{~m}$ laps during men's and women's mile world record performances, and (B) world records set by El Guerrouj and Hassan. ${ }^{*} p<0.05 ;{ }^{* * *} p<0.001$.

Championship races were used for the achievement of $45.83 \%$ and $80 \%$, and $31.58 \%$ and $63.63 \%$, of men's and women's $800 \mathrm{~m}$ and $1500 \mathrm{~m}$ WRs, respectively. The remaining ones were set during meet races.

\section{Discussion}

The aims of the current study were to describe and compare the pacing patterns of alltime $800 \mathrm{~m}, 1500 \mathrm{~m}$ and mile running WRs to determine if differences exist between sexes and identify whether $800 \mathrm{~m}$ and $1500 \mathrm{~m}$ WRs were broken during either championship or meet races. Given that pacing patterns in women's $800 \mathrm{~m}$ and $1500 \mathrm{~m}$ WRs were not previously studied to the best of the authors' knowledge, the most important finding is that a very similar pacing approach was followed in these events when compared to men. However, pacing strategies in the mile event differed among sexes. In this way, both men and women's $800 \mathrm{~m}$ WRs displayed a positive pacing profile (i.e., characterized by a decreasing speed throughout the race), while both men and women's $1500 \mathrm{~m}$, and women's mile WRs were characterized by a U-shaped pacing profile (i.e., displaying a faster-slower-slower-faster pattern for each successive lap). Finally, men's mile WRs followed a reverse-J-shaped pacing profile characterized by a very fast start, a slower middle part of the race, and an end-spurt, which was found to be slower than the first lap of the race.

The positive pacing profile observed in both men and women's $800 \mathrm{~m}$ WRs is consistent with findings from a previous study which examined the men's $800 \mathrm{~m}$ WRs set until 1997 [11]. This pacing profile was found to be the same after including the three WRs set by Rudisha. Moreover, the current men's WR was characterized by an extremely positive pacing profile (i.e., the speed decreases throughout the race) in which the first $200 \mathrm{~m}$ and $400 \mathrm{~m}$ splits were covered in $23.4 \mathrm{~s}$ and $49.28 \mathrm{~s}$, respectively, with a final lap of $51.63 \mathrm{~s}$ (Figure 1B) [14,17]. This pattern observed during $800 \mathrm{~m}$ WRs can be also considered a seahorse-shaped [20] pacing profile (see Figure 1). Similarly, this seahorse-shaped profile was also observed during the qualifying rounds and final races at the 2013 and 2017 WA Championships and 2016 Olympic Games in which the fastest speed was achieved over $200 \mathrm{~m}$, followed by a deceleration to $300 \mathrm{~m}$, a constant speed to $500 \mathrm{~m}$, another acceleration to $600 \mathrm{~m}$, and then maintenance or deceleration up to the finish line [20]. Moreover, no substantial differences seem to exist between the pacing profile used to achieve WRs and that used to succeed during global championship races in the $800 \mathrm{~m}$ event. In this regard, a more positive strategy in elite and world-class speed-based milers than endurance-based milers was observed not only during competitions, but also during their training practices [21]. This would suggest an influence of training background on pacing patterns that warrants further research.

The lack of sex-based differences in pacing profiles found in $800 \mathrm{~m} \mathrm{WRs}$ is not consistent with results from a previous study analyzing 142 of the $800 \mathrm{~m}$ season best performances of world-class athletes during meet races [22]. This previous study found that the first 
$200 \mathrm{~m}$ was always the fastest. However, whereas men tended to decrease the pace progressively throughout the race, there were no pace differences between the last three $200 \mathrm{~m}$ laps for women. In this way, men covered the second $200 \mathrm{~m}$ segment at a relatively faster speed than women. This sex-based difference was attributed to the lower performance level displayed during women's races, which may have influenced their relatively slower second $200 \mathrm{~m}$ segment [22]. Nonetheless, these differences in performance level do not seem to affect pacing profiles during $800 \mathrm{~m} \mathrm{WRs,} \mathrm{as} \mathrm{they} \mathrm{represent} \mathrm{the} \mathrm{greatest} \mathrm{performances}$ achieved ever for both men and women. However, an important sex-based difference was found regarding the greater number of WRs set during championship races by women than men (i.e., $80 \%$ vs. $45.83 \%$ of the WRs analyzed for women and men, respectively). This finding emphasizes the competitiveness of the $800 \mathrm{~m}$ WRs set by women, as, during championship races, the use of pacemakers is not allowed. Of note, $800 \mathrm{~m}$ major championships involve participation in different qualifying rounds within just a few days in order to be able to run the final race, which, in turn, leads to high levels of physical fatigue, thus preventing runners from being in the same resting state to that typically experienced during meet races.

Similar to findings from previous studies analyzing men's $1500 \mathrm{~m}$ [12] and mile [13] WRs broken until 1999 and 1998, respectively, a U-shaped pacing strategy was found on average during both men and women's $1500 \mathrm{~m}$ and women's mile WRs. However, contrary to the results reported by Noakes et al. [13], a reverse-J-shaped rather than U-shaped pacing strategy was found for the latest 32 men's WRs. These represent a quite different pacing profile to that observed in the $800 \mathrm{~m}$ event and highlights a shift from a positive/seahorseshaped strategy toward a U-shaped pacing strategy as long as the event distance increases. In the $800 \mathrm{~m}$ event, the initial speed clearly exceeds the fatigue threshold running speed, i.e., the fastest speed that can be maintained throughout any entire event, which is determined by physiological limits, such as pulmonary gas exchange, blood lactate concentrations, and acid base status [23]. In this manner, $800 \mathrm{~m}$ runners breaking WRs typically reach their metabolic limit to compensate for the lost time later in the race [11].

However, during the $1500 \mathrm{~m}$ and mile WRs, the fatigue threshold is not surpassed to that extent, as milers are able to display a fast end spurt in the latest stages of the race, showing a greater ability than $800 \mathrm{~m}$ runners to recover from the first 'fast' $400 \mathrm{~m}$ lap [21]. Furthermore, the progression in pacing profiles of men's mile WRs is characterized by a shift from U-shaped toward a more even pacing strategy [7], showing, therefore, the high importance of not surpassing early the fatigue-threshold speed in order to optimize performance in these middle-distance running events. By contrast to the $800 \mathrm{~m}$ event, the pacing profiles obtained in both men and women $1500 \mathrm{~m}$ WRs substantially differed from those observed during the qualifying rounds and final races at the 2013 and 2017 WA Championships and 2016 Olympic Games, which were characterized by a J-shaped pacing profile [20]. This pacing profile involves important variations in pace during the race [24] in which runners adopt a moderate initial speed during the first lap, decelerate the speed for the second lap, increase the speed between $700 \mathrm{~m}$ and $1300 \mathrm{~m}$, and maintain or decelerate their speed during the final $200 \mathrm{~m}$ [20]. Indeed, success during the men's $1500 \mathrm{~m}$ qualifying rounds of the 2017 WA Championships was related to being able to generate a fast end spurt during the last $300 \mathrm{~m}$ of the race [25]. In this manner, during championship races in which the main goal is achieving either a qualifying position to participate in the next round or the highest possible position during the final race, the end spurt is typically faster and the middle part of the race is slower than during races in which WRs are achieved [24]. However, despite a U-shaped pacing profile being found for all $1500 \mathrm{~m}$ and mile WRs, both current men's $1500 \mathrm{~m}$ and mile WRs set by Moroccan Hicham El Guerrouj displayed a J-shaped pacing profile (Figures 2B and 3B), similar to that observed during championship races [20]. In addition, contrary to the findings by Noakes et al. [13], who concluded that no pace differences were found between the first $409 \mathrm{~m}$ lap and last $400 \mathrm{~m}$ lap for the latest 32 men's mile WRs, we observed that the first lap was faster than the last lap, thus revealing a reverse-J-shaped pacing strategy. These different 
results in the pacing strategy used for the same WRs can be explained by the different type of analysis conducted between studies. While Noakes et al. [13] calculated the differences between the average lap time, we analyzed the differences between the average lap speed, which is more appropriate for relative comparisons.

Similar to findings in the $800 \mathrm{~m}$ event, no sex-based differences were found in $1500 \mathrm{~m}$ and mile WRs. Nonetheless, a reverse-J-shaped pacing strategy in which the first $409 \mathrm{~m}$ lap was faster than the last $400 \mathrm{~m}$ lap was adopted in men's mile WRs, being different from the U-shaped profile observed for women. Furthermore, also similar to the findings in the $800 \mathrm{~m}$ event, a greater \% of women's $1500 \mathrm{~m}$ WRs were achieved during championship races (i.e., $63.63 \%$ vs. $31.58 \%$ of the WRs analyzed for women and men, respectively). These sex-based differences found are in agreement with findings from several studies, indicating that women are better pacers than men, as they tend to slow less during the latest stages of long-distance races, such as $10 \mathrm{~km}$ road races [26], cross-country races [27] and marathons [28,29]. Rather than attributing the greater \% of women's WRs achieved during championship races to sex-related physiological characteristics, such as those proposed for longer distance events (i.e., a greater amount of type I muscle fibers in women than men [30]), the most likely explanation may be the lower density in performance level in women's races, which may have allowed to set faster initial paces without a serious threat of being defeated by a competitor of similar ability [8]. In addition, a greater number of WRs were beaten in championship races during the $800 \mathrm{~m}$ rather than the $1500 \mathrm{~m}$ events. Given that the use of pacemakers is scarce in championship races, these results suggest that the longer the distance of the event, the more important the use of pacemakers in order to achieve a fastest performance. This finding clearly emphasizes the high mental cost of the decision-making process represented by continuously setting the pace during endurance events, apart from the benefits derived from drafting $[3,16]$.

The lack of both official electronic splits for some of the WRs analyzed and the exclusion of a substantial amount of WRs, especially in women events, have to be acknowledged as the main limitations of the present study. In this way, outcomes derived from the statistical comparisons between lap times during women's mile WRs may be affected to some extent by the reduced sample size already available.

\section{Conclusions}

A positive pacing strategy characterized by a fast $200 \mathrm{~m}$, a deceleration to $600 \mathrm{~m}$, and another deceleration to the finish line was found during $800 \mathrm{~m}$ WRs. A U-shaped pacing strategy was found on average during $1500 \mathrm{~m}$ and women's mile WRs. A reverse-J-shaped pacing strategy characterized by a fastest-slower-slower-faster pattern was followed during men's mile WRs. No relevant sex-based differences in pacing strategy were found in any of these three middle-distance running events. Women achieved a greater $\%$ of $800 \mathrm{~m}$ WRs than men during championship races. Similarly, women also set a greater \% of $1500 \mathrm{~m}$ WRs than men during championship races. Therefore, as long as the distance of the event increases, the number of WRs broken at championship races decreases.

\section{Practical Applications}

Men and women's middle-distance runners aiming to break the $800 \mathrm{~m}$ WR should cover a fast initial $200 \mathrm{~m}$ segment of the race while trying to lose the least possible speed during the rest of the race. On the other hand, men and women runners attempting to achieve the $1500 \mathrm{~m}$ and mile WRs may adopt either a U-shaped pacing profile characterized by a faster-slower-slower-faster pattern for each successive lap, or an even pacing strategy in which the fatigue threshold speed should not be surpassed. However, a more even pacing strategy may be likely more effective for doing so [7]. Women's $800 \mathrm{~m}$ runners peaking for a major championship may consider breaking a WR while chasing the gold medal in the case that the pre-expected performance difference with their competitors is substantial. This pre-expectation can be considered according to the differences between the athletes season best times and those from the closest rivals, and through the information obtained 
from the performance achieved during the last competitions prior to the championship. For men, in the case that performance differences between the theoretically best male $800 \mathrm{~m}$ runner and the rest of the runners are very large, such as that exhibited by David Rudisha and his rivals at the 2012 London Olympic Games, a WR attempt may be also achieved.

Author Contributions: Conceptualization, A.C. and F.G.-M.; methodology, A.C., D.B. and F.G.-M.; formal analysis, A.C., D.B. and F.G.-M.; writing-original draft preparation, A.C., J.M.G.-R. and F.G.-M.; writing-review and editing, A.C., J.M.G.-R., F.G.-M. and D.B. All authors have read and agreed to the published version of the manuscript.

Funding: This research received no external funding.

Institutional Review Board Statement: The study was conducted according to the guidelines of the Declaration of Helsinki. Institutional review board approval for this study was waived with regard to informed consent because these data are in the public domain.

Informed Consent Statement: Not applicable.

Data Availability Statement: Not applicable.

Conflicts of Interest: The authors declare no conflict of interest.

\section{References}

1. Foster, C. Vo2max and training indices as determinants of competitive running performance. J. Sports Sci. 1983, 1, 13-22. [CrossRef]

2. Gibson, A.S.C.; de Koning, J.J.; Thompson, K.G.; Roberts, W.O.; Micklewright, D.; Raglin, J.; Foster, C. Crawling to the Finish Line: Why do Endurance Runners Collapse?: Implications for Understanding of Mechanisms Underlying Pacing and Fatigue. Sports Med. 2013, 43. [CrossRef]

3. Casado, A.; Moreno-Pérez, D.; Larrosa, M.; Renfree, A. Different psychophysiological responses to a high-intensity repetition session performed alone or in a group by elite middle-distance runners. Eur. J. Sport. Sci. 2019, 19, 1045-1052. [CrossRef]

4. Renfree, A.; Casado, A.; Pellejero, G.; Hanley, B. More pace variation and pack formation in successful world-class 10,000-m runners than in less successful competitors. Int. J. Sports Physiol. Perform. 2020, 15, 1369-1376. [CrossRef]

5. Pugh, L.G.C.E. The influence of wind resistance in running and walking and the mechanical efficiency of work against horizontal or vertical forces. J. Physiol. 1971, 213, 255-276. [CrossRef] [PubMed]

6. Renfree, A.; Casado, A. Athletic races represent complex systems, and pacing behavior should be viewed as an emergent phenomenon. Front. Physiol. 2018. [CrossRef] [PubMed]

7. Foster, C.; De Koning, J.J.; Thiel, C. Evolutionary pattern of improved 1-mile running performance. Int. J. Sports Physiol. Perform. 2014, 9, 715-719. [CrossRef]

8. Casado, A.; Hanley, B.; Jiménez-Reyes, P.; Renfree, A. Pacing profiles and tactical behaviors of elite runners. J. Sport Heal. Sci. 2020. [CrossRef]

9. Díaz, J.J.; Fernández-Ozcorta, E.J.; Santos-Concejero, J. The influence of pacing strategy on marathon world records. Eur. J. Sport. Sci. 2018, 18, 781-786. [CrossRef]

10. Foster, C.; de Koning, J.J.; Thiel, C.; Versteeg, B.; Boullosa, D.A.; Bok, D.; Porcari, J.P. Beating Yourself: How Do Runners Improve Their Own Records? Int. J. Sports. Physiol. Perform. 2019, 15, 437-440. [CrossRef] [PubMed]

11. Tucker, R.; Lambert, M.I.; Noakes, T.D. An analysis of pacing strategies during men's world-record performances in track athletics. Int. J. Sports Physiol. Perform. 2006, 1, 233-245. [CrossRef] [PubMed]

12. Casado, A.; García-Manso, J.M.; Romero-Franco, N.; Martínez-Patiño, M.J. Pacing strategies during male $1500 \mathrm{~m}$ running world record performances. Res. Sports Med. 2021. [CrossRef]

13. Noakes, T.D.; Lambert, M.I.; Hauman, R. Which lap is the slowest? An analysis of 32 world mile record performances. Br. J. Sports Med. 2009, 43, 760-764. [CrossRef]

14. Sandford, G.N.; Pearson, S.; Allen, S.V.; Malcata, R.M.; Kilding, A.E.; Ross, A.; Laursen, P.B. Tactical behaviors in men's 800-m olympic and world-championship medalists: A changing of the guard. Int. J. Sports Physiol. Perform. 2018, 13, 246-249. [CrossRef] [PubMed]

15. Díaz, J.J;; Fernández-Ozcorta, E.J.; Torres, M.; Santos-Concejero, J. Men vs. women world marathon records' pacing strategies from 1998 to 2018. Eur. J. Sports Sci. 2019, 19, 1297-1302. [CrossRef]

16. Renfree, A.; Martin, L.; Micklewright, D.; St Clair Gibson, A. Application of decision-making theory to the regulation of muscular work rate during self-paced competitive endurance activity. Sports Med. 2014, 44, 147-158. [CrossRef] [PubMed]

17. Hymans, R.; Matrahazi, I. (Eds.) Progression of IAAF World Records; IAAF Atletics: Monte Carlo, Monaco, 2015.

18. Cohen, J. Statistical Power Analysis for the Behavioural Sciences, 2nd ed.; Lawrence Earlbaum Associates: Hillsdale, NJ, USA, 1988.

19. Cohen, J. Statistical Power Analysis. Curr. Dir. Psychol. Sci. 1992, 1, 98-101. [CrossRef] 
20. Hanley, B.; Stellingwerff, T.; Hettinga, F.J. Successful pacing profiles of olympic and IAAF World Championship middle-distance runners across qualifying rounds and finals. Int. J. Sports Physiol. Perform. 2019, 14, 894-901. [CrossRef]

21. Casado, A.; Renfree, A.; Jaenes-Sánchez, J.C.; Cuadrado-Peñafiel, V.; Jiménez-Reyes, P. Differentiating endurance-and speedadapted types of elite and world class milers according to biomechanical, pacing and perceptual responses during a sprint interval session. Int. J. Environ. Res. Public Health 2021, 18, 2448. [CrossRef] [PubMed]

22. Filipas, L.; Ballati, E.N.; Bonato, M.; La Torre, A.; Piacentini, M.F. Elite male and female 800-m runners $\Leftrightarrow$ display of different pacing strategies during season-best performances. Int. J. Sports Physiol. Perform. 2018, 13, 1344-1348. [CrossRef] [PubMed]

23. Fukuba, Y.; Whipp, B.J. A metabolic limit on the ability to make up for lost time in endurance events. J. Appl. Physiol. 1999, 87, 853-861. [CrossRef]

24. Thiel, C.; Foster, C.; Banzer, W.; de Koning, J. Pacing in Olympic track races: Competitive tactics versus best performance strategy. J. Sports Sci. 2012, 30, 1107-1115. [CrossRef] [PubMed]

25. Casado, A.; Renfree, A. Fortune Favors the Brave. Tactical Behaviors in the Middle Distance Running Events at the 2017 IAAF World Championships. Int. J. Sports Physiol. Perform. 2018, 13, 1-22. [CrossRef] [PubMed]

26. Deaner, R.O.; Addona, V.; Carter, R.E.; Joyner, M.J.; Hunter, S.K. Fast men slow more than fast women in a 10 kilometer road race. PeerJ 2016, 4, e2235. [CrossRef] [PubMed]

27. Deaner, R.O.; Lowen, A. Males and Females Pace Differently in High School Cross-Country Races. J. Strength Cond. Res. 2016, 30, 2991-2997. [CrossRef] [PubMed]

28. Deaner, R.O.; Carter, R.E.; Joyner, M.J.; Hunter, S.K. Men are more likely than women to slow in the marathon. Med. Sci. Sports Exerc. 2014, 47, 607-616. [CrossRef]

29. March, D.S.; Vanderburgh, P.M.; Titlebaum, P.J.; Hoops, M.L. Age, sex, and finish time as determinants of pacing in the marathon. J. Strength Cond. Res. 2011, 25, 386-391. [CrossRef]

30. Hunter, S.K. Sex differences in human fatigability: Mechanisms and insight to physiological responses. Acta Physiol. 2014, 210, 768-789. [CrossRef] 